\title{
Comparative Study of the Effect of Structural Parameters on the Flexibility of Endovascular Stent Grafts
}

\author{
Ying Guan $\mathbb{D},{ }^{1}$ Jing Lin $\mathbb{D},{ }^{1}$ Zhihui Dong $\mathbb{D}^{2},{ }^{2}$ and Lu Wang $\mathbb{D}^{1}$ \\ ${ }^{1}$ Key Laboratory of Textile Science and Technology, Ministry of Education, College of Textiles, \\ Donghua University, 2999 North Renmin Road, Songjiang, Shanghai 201620, China \\ ${ }^{2}$ Zhongshan Hospital, Fudan University, Shanghai 200032, China \\ Correspondence should be addressed to Lu Wang; wanglu@dhu.edu.cn
}

Received 9 November 2017; Accepted 18 February 2018; Published 1 April 2018

Academic Editor: Amit Bandyopadhyay

Copyright (c) 2018 Ying Guan et al. This is an open access article distributed under the Creative Commons Attribution License, which permits unrestricted use, distribution, and reproduction in any medium, provided the original work is properly cited.

\begin{abstract}
The complication of stent graft-induced new entry (SINE) after thoracic endovascular aortic repair (TEVAR) may be caused by the spring-back force of both ends of the stent grafts. Spring-back force, which is exerted by the curvature and ends of stent grafts on the greater wall of the aorta, suggests poor flexibility. Research on stent graft flexibility via design optimization has been widely disregarded. Thus, this study investigates the relationship between stent graft structure and flexibility by measuring bending and spring-back forces. Stent spacing $(5,10$, and $15 \mathrm{~mm})$, apex angle $\left(30^{\circ}\right.$ and $\left.45^{\circ}\right)$, and strut configuration $(\mathrm{Z}$ - and M-stented) were considered for the structural parameters. The overall tendency of spring-back and bending forces was similar. The stent graft with $15 \mathrm{~mm}$ spacing attained the lowest force level. The force difference between samples with $30^{\circ}$ and $45^{\circ}$ apex angles became prominent as the curving angle increased. The sample with $45^{\circ}$ stent apex attained low force value. The Z-stented graft obtained a lower force than the M-stented graft with the same number of struts per hoop. Consequently, optimal flexibility was obtained when the structural design was characterized by long stent spacing, big stent apex angle, and Z-type strut configuration.
\end{abstract}

\section{Introduction}

Thoracic endovascular aortic repair (TEVAR) technology for thoracic dissection and aneurysm treatment has developed rapidly since the first successful thoracic stent graft device application [1]. And subsequent short- and midterm clinical results were promising compared with those of open surgery [2]. However, not all long-term outcomes were fully satisfied $[3,4]$. Thus, further research is needed to reduce incidences of long-term complications.

Rigid thoracic stent grafts cannot fully conform with the anatomy of the aortic arch, although they work well for descending thoracic aorta [5]. The complex aorta arch morphology can lead to a mismatch between thoracic aorta and stent grafts, and thus, potential risks of bird beak resulting in endoleak and stent graft collapse may occur [6]. Moreover, the short angulated necks of abdominal aortic aneurysms demand high-level stent graft flexibility, stent graft displacement, and kinking can cause limb occlusions
[7-9]. Therefore, stent grafts should be flexible and conformable with the host artery [10-14].

Stent graft-induced new entry (SINE) is a new tear caused by the rigid stent graft itself when ends spring back to the initial form after they are passively bent along the aorta arch $[15,16]$. SINE may be proximal or distal. Dong et al. [15] posited that spring-back force could potentially cause SINE, especially in the proximal end. Proximal SINE was observed when the oversizing rate was only $3 \%$, and this could decrease radial force to the maximum extent [15]. Thus, radial force was disassociated with proximal SINE and instead was considered as the main factor of distal SINE [15]. In general, spring-back force is the force exerted by stent grafts acting on the greater curve when placed in a tortuous arterial anatomy, such as aorta arch and popliteal artery.

No unified evaluation index estimates the flexibility of stent graft at present. Different evaluation indexes, such as percentage change in diameter [17], bending force [18], and spring-back force, were presented in literature. Bending 
force is the force to bend a stent graft, whereas spring-back force is the force to recover a straight stent graft after bending. Flexibility evaluation can be done by finite element analysis (FEA) [19] or in vitro experimental studies. Demanget et al. [9] modeled seven commercial aortic stent grafts by FEA to assess their flexibility and calculate luminal reduction rate. Only a few FEA studies were conducted on the mechanics of stent grafts, although several other FEA studies have focused on stents alone. The gaps may be attributed to the complexity of the stent graft, which is a combination of a rigid stent and a soft textile tubular graft [20]. Several assumptions were offered to simplify numerical work. However, this could decrease the result accuracy. Qualitative and quantitative in vitro experimental studies were also conducted. Singh and Wang [8] estimated the bending behavior of segmented and plain knit stents by bent configuration observation immediately and bending moment with the free-bending end of the stents at $90^{\circ}$ from the stent axis. Freitas et al. [21] estimated the percentage change in the diameter at $90^{\circ}$, which represents the flexibility of weft-knitted and braided stents. Hirdes et al. [22] suggested that measuring the force exerted by the stent from bending to straightening (i.e., spring-back force in this study) is much more meaningful than the force to bend it (i.e., bending force). Spring-back force was measured by recording the force required to keep the stent at the bending angle of $20^{\circ}$ at $20 \mathrm{~mm}$ from the bending point; however, load cell foot was not placed vertical to the sample. Thus, the force tested was not the real spring-back force. Isayama et al. [23] and Zou et al. [24] used a similar method in the vertical orientation to test the spring-back force of stents and stent grafts. However, only the forces under limited curving angles were tested.

The structure of stent design determines the behavior of stent graft. Although a number of research have reported the importance of flexibility, majority of these studies only compared the different stent strut types and disregarded the optimal stent design. Demanget et al. [25] studied the relationship between stent graft design and flexibility by comparing the flexibility of $\mathrm{Z}$ - and spiral-stented grafts via FEA. However, the effects of $Z$ - and spiral-stented graft structures on flexibility were unreported. Clinical and animal trails also confirmed the relationship of flexible devices and low incidence of complications after surgery [26, 27]. However, evaluating flexibility as a design parameter of stent grafts was not discussed in detail. Moreover, the structures of stent grafts and their effects on flexibility have not yet been tested via animal trails. Several difficulties are encountered in designing flexible stent grafts. Therefore, a feasibility study on the relationship between the structural parameters and flexibility of stent grafts is necessitated. Results may particularly benefit Z-stented devices, which is currently a common design of several commercial products'.

The present study tested bending force and spring-back force by employing a newly designed device under a continuous curving angle. The force tester foot was placed vertical to the surface of the sample. The two forces (bending and spring-back) served as indicators of stent graft flexibility. Both forces were estimated and compared using stent grafts with different structural characteristics. Consequently, the optimal design factor that may affect the flexibility of stent grafts is established.

\section{Materials and Methods}

2.1. Stent Grafts. The structural parameters (stent spacing: 5, 10 , and $15 \mathrm{~mm}$; stent apex angles: $30^{\circ}$ and $45^{\circ}$; and stent strut configuration: Z- and M-stented) of the stent grafts were studied. The schematics of the structural parameters of Zand $\mathrm{M}$-stented grafts are illustrated in Figure 1. The height of the single Z-stent strut was set constant $(10.96 \mathrm{~mm})$ while stent spacing was placed shorter, similar, and longer than stent struts. The stent apex angle was selected on the basis of commonly used commercial stent grafts. Currently, several commercial stent grafts have adopted the M-type strut configuration, and Z-type strut is still commonly used.

Seven stent graft prototypes were considered in this study. The prototypes were divided into three groups: A, B, and C. The three samples in Group A were labeled A11, A22, and A33; the two samples in Group B were labeled B13 and B23; and the two samples in Group C were labeled as C13 and $\mathrm{C} 23$.

Polyester seamless tubular grafts were fabricated at the Biomedical Textile Research Center, Donghua University, Shanghai (China). Warp and weft yarns were obtained from Suzhou Suture Needle Co. The yarns and tubular fabric characteristics are presented in Table 1. All tubular grafts were plain weave, and parameter difference (i.e., linear density of weft yarn) was observed in Group A only. The structural parameters of woven seamless tubular grafts in this study were similar to those of commercially available devices [28].

The structural parameters of nitinol stents (Micro-Tech Co. Ltd., Nanjing, China) are shown in Table 2. The stent grafts of Group A and B were of the Z-stented type, whereas the stent grafts of Group $\mathrm{C}$ were $\mathrm{M}$-stented. Stent spacing variation $(5,10$, and $15 \mathrm{~mm}$ ) were observed in Group A, whereas apex angle variation $\left(30^{\circ}\right.$ and $\left.45^{\circ}\right)$ was observed in Group B. Other stent parameters (except for group-level variations) were the same. Thus, only one variable exists in each group. Stents and seamless tubular grafts were stitched together by multifilament polyester-braided 5-0 suture (Jinhuan Medical Co., Shanghai, China) at the Biomedical Textile Research Center.

2.2. Bending Force and Spring-Back Force. Bending force and spring-back force were measured with a new device [29] developed at Donghua University (Figure 2). The device was composed of a motor and columns for stent graft mounting. The columns could rotate with the motor at constant speeds. The stent-graft sample was tightly fixed to the cylindrical column (COLUMN). COLUMN rotated around a horizontal center line at the right end of plane $E$, which in this study was set as the design bending point of the stent graft. During the test, the load cell foot was in constant contact with the stent grafts to ensure that bending force and spring-back force could be recorded continuously regardless of the curving angle. 


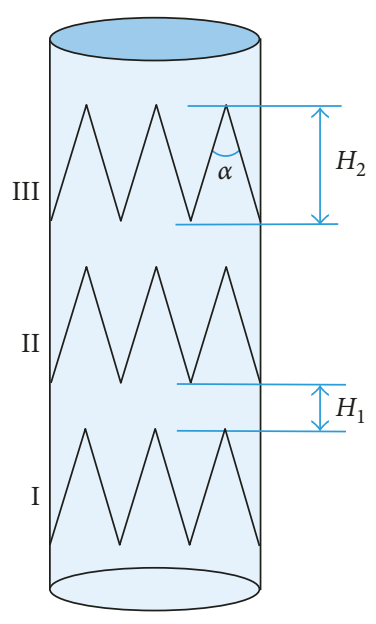

(a)

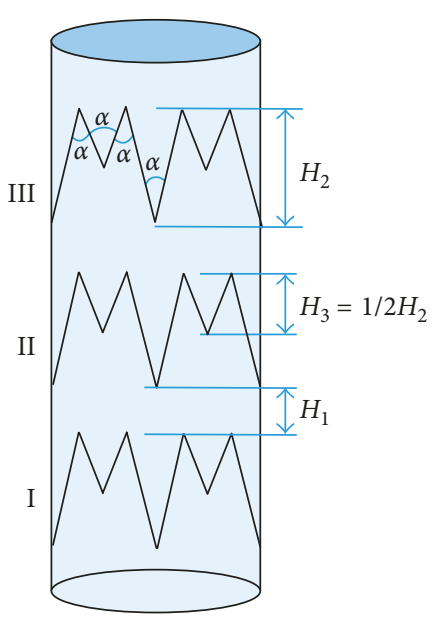

(b)

FIGURE 1: Schematics of (a) Z-stented and (b) M-stented grafts. ( $H_{1}$ refers to the stent spacing, $H_{2}$ refers to the height of one stent strut, $H_{3}$ is half of $\mathrm{H}_{2}$, and $\alpha$ refers to the stent apex angle.)

TABLe 1: Textile structural parameters of seamless tubular grafts.

\begin{tabular}{|c|c|c|c|c|c|c|c|}
\hline \multirow{2}{*}{$\begin{array}{l}\text { Stent } \\
\text { graft } \\
\text { number }\end{array}$} & \multirow{2}{*}{$\begin{array}{c}\text { Tubular } \\
\text { graft } \\
\text { number }\end{array}$} & \multicolumn{2}{|c|}{$\begin{array}{l}\text { Yarn linear density (D } \\
\text { (denier)/filament count) }\end{array}$} & \multirow{2}{*}{$\begin{array}{c}\text { Fabric } \\
\text { construction }\end{array}$} & \multicolumn{2}{|c|}{$\begin{array}{c}\text { Fabric count } \\
(\text { ends } / \mathrm{mm} \times \text { picks } / \mathrm{mm})\end{array}$} & \multirow{2}{*}{$\begin{array}{c}\text { Wall } \\
\text { thickness } \\
(\mathrm{mm})\end{array}$} \\
\hline & & Warp & Weft & & Warp & Weft & \\
\hline A11 & G1 & $30 \mathrm{D} / 1 \mathrm{f}$ & $30 \mathrm{D} / 1 \mathrm{f}$ & 1/1 plain & $13.1 \pm 0.2$ & $8.2 \pm 0.2$ & $0.144 \pm 0.006$ \\
\hline $\mathrm{A} 22$ & G2 & $30 \mathrm{D} / 1 \mathrm{f}$ & $20 \mathrm{D} / 12 \mathrm{f}$ & $1 / 1$ plain & $13.7 \pm 0.2$ & $7.2 \pm 0.2$ & $0.115 \pm 0.002$ \\
\hline A33 & G3 & $30 \mathrm{D} / 1 \mathrm{f}$ & $30 \mathrm{D} / 12 \mathrm{f}$ & 1/1 plain & $13.9 \pm 0.3$ & $6.6 \pm 0.5$ & $0.125 \pm 0.002$ \\
\hline B13 & G3 & $30 \mathrm{D} / 1 \mathrm{f}$ & $30 \mathrm{D} / 12 \mathrm{f}$ & 1/1 plain & $13.9 \pm 0.3$ & $6.6 \pm 0.5$ & $0.125 \pm 0.002$ \\
\hline $\mathrm{B} 23$ & G3 & $30 \mathrm{D} / 1 \mathrm{f}$ & $30 \mathrm{D} / 12 \mathrm{f}$ & 1/1 plain & $13.9 \pm 0.3$ & $6.6 \pm 0.5$ & $0.125 \pm 0.002$ \\
\hline $\mathrm{C} 13$ & G3 & $30 \mathrm{D} / 1 \mathrm{f}$ & $30 \mathrm{D} / 12 \mathrm{f}$ & 1/1 plain & $13.9 \pm 0.3$ & $6.6 \pm 0.5$ & $0.125 \pm 0.002$ \\
\hline $\mathrm{C} 23$ & G3 & $30 \mathrm{D} / 1 \mathrm{f}$ & $30 \mathrm{D} / 12 \mathrm{f}$ & 1/1 plain & $13.9 \pm 0.3$ & $6.6 \pm 0.5$ & $0.125 \pm 0.002$ \\
\hline
\end{tabular}

TABLE 2: Structural parameters of stents.

\begin{tabular}{|c|c|c|c|c|c|c|}
\hline $\begin{array}{l}\text { Stent graft } \\
\text { number }\end{array}$ & $\begin{array}{c}\text { Stent strut } \\
\text { configuration }\end{array}$ & $\begin{array}{l}\text { Angle of stent } \\
\text { apex, } \alpha\left(^{\circ}\right)\end{array}$ & $\begin{array}{c}\text { Stent spacing, } H_{1} \\
(\mathrm{~mm})\end{array}$ & $\begin{array}{l}\text { Height of one stent strut, } \\
\qquad \mathrm{H}_{2}(\mathrm{~mm})\end{array}$ & $\begin{array}{l}\text { Number of struts } \\
\text { per hoop }\end{array}$ & $\begin{array}{l}\text { Diameter } \\
(\mathrm{mm})\end{array}$ \\
\hline A11 & $\mathrm{Z}$ & 35 & 5 & 10.96 & 5 & 11 \\
\hline A22 & $\mathrm{Z}$ & 35 & 10 & 10.96 & 5 & 11 \\
\hline A33 & Z & 35 & 15 & 10.96 & 5 & 11 \\
\hline B13 & $\mathrm{Z}$ & 30 & 10 & 10.96 & 6 & 11 \\
\hline B23 & Z & 45 & 10 & 10.96 & 4 & 11 \\
\hline $\mathrm{C} 13$ & M & 30 & 10 & 10.96 & 4 & 11 \\
\hline C23 & $\mathrm{M}$ & 40 & 10 & 10.96 & 3 & 11 \\
\hline
\end{tabular}

This device was designed to avoid a nonvertical test condition between the load cell foot and stent-graft surface on the basis of results of past research. The design also aimed to gather bending and spring-back force data for different curving angles.

All seven stent-graft prototypes utilized three stent wires labeled as I, II, and III. The right end of COLUMN (plane E) is located in the middle of the unstented zone between stent wires I and II, as shown in Figure 3(c). Two stent wires were free-bending (II and III). The bending and spring-back force test was positioned at the right end of stent wire III located at the stent apex. The free-bending stent wires remained motionless while the fixed portion rotated. Bending arm length was defined as the axial distance between plane $E$ and the force testing position. The bending arm lengths of each stent graft are shown in Table 3.

Bending force on the right end of stent wire III was recorded when COLUMN rotated from the horizontal position at the constant speed of $1.25 \mathrm{r} / \mathrm{min}$. The stent graft shifted from straight to bent position. The angle between the horizontal position and the bent position is represented by curving angle $\theta$, which can be measured by referring to the center line of COLUMN in two positions, as shown in Figure 3(a). Spring-back force was measured following the same procedure but in the reverse order (i.e., clockwise direction when COLUMN was rotated from a certain curving angle $\theta$ to the horizontal position with the same speed). The stent graft shifted from bent to straight position (Figure 3(b)). In 


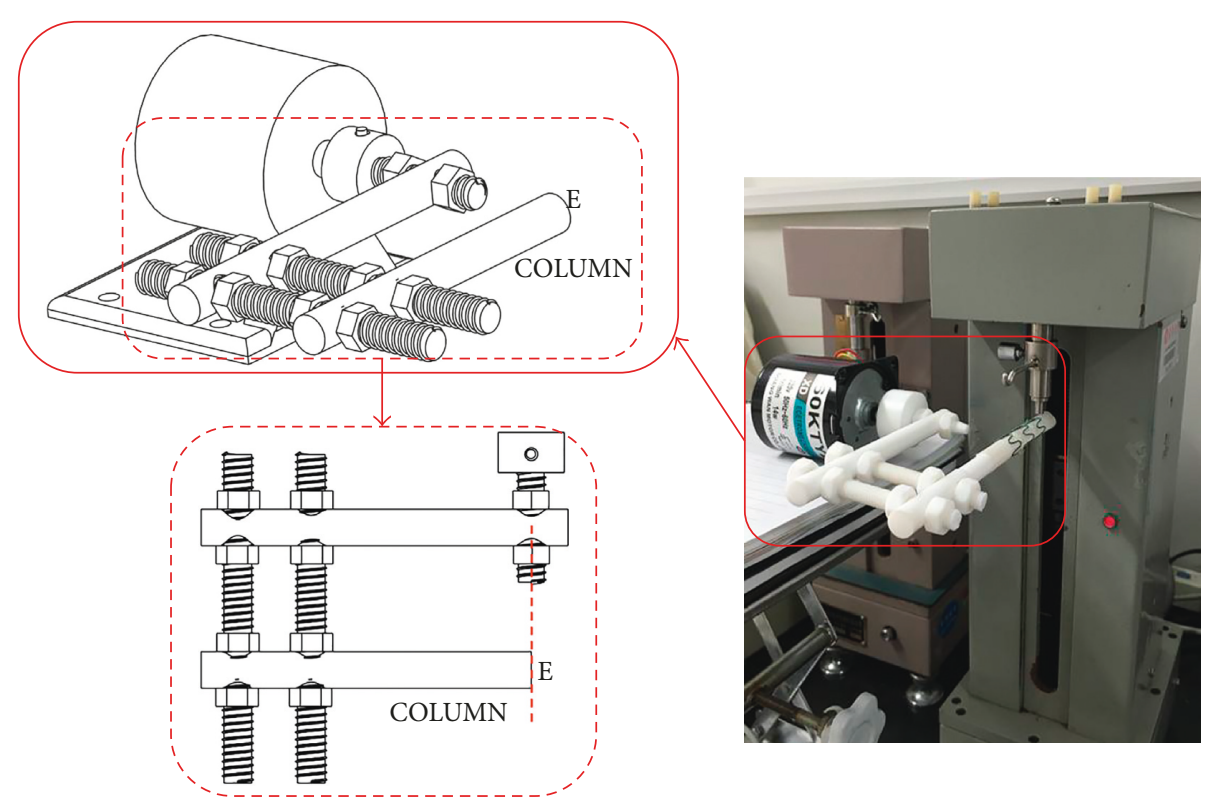

FIgURE 2: Device to mount stent graft for the bending and spring-back force tests.

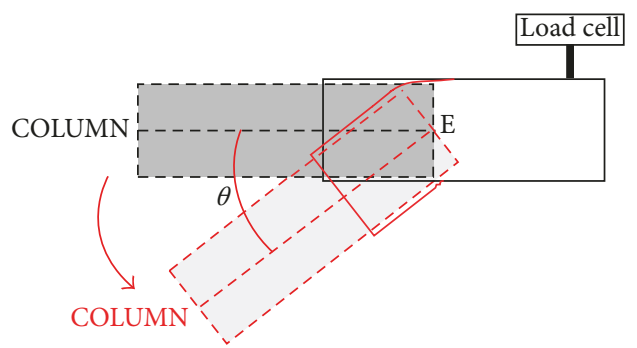

(a)

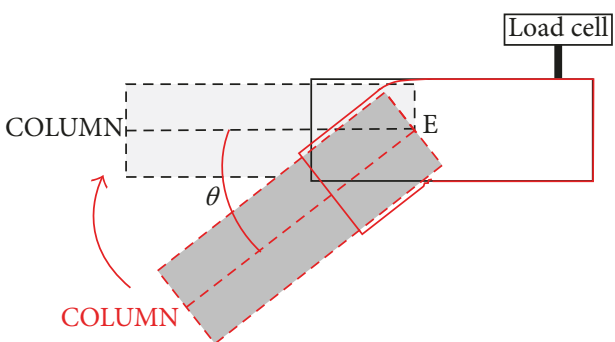

(b)

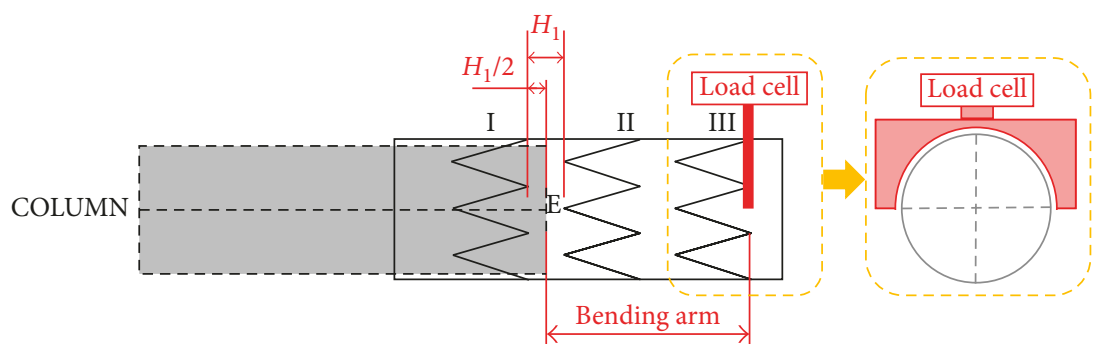

(c)

FIGURE 3: Schematic of test methods of (a) bending force, (b) spring-back force, and (c) stent graft fixation on COLUMN.

summary, this study recorded bending and spring-back forces under a continuous curving angle, in which the load cell foot was positioned perpendicular to the samples.

The bending and spring-back forces of seamless tubular grafts were also measured using the same testing methods and parameters mentioned above. COLUMN was inserted onto the tubular graft. The bending arm of the tubular grafts was the same with those of the stent grafts.

2.3. Statistical Analysis. Results were statistically analyzed by SPSS ver. 19 (SPSS Inc., Chicago, IL, USA). For the one-way ANOVA, a significant difference exists if $p$ value is $<0.05$.
TABLE 3: Bending arm lengths of stent grafts $(\mathrm{mm})$.

\begin{tabular}{ccccccr}
\hline A11 & A22 & A33 & B13 & B23 & C13 & C23 \\
\hline 29.42 & 36.92 & 44.42 & \multicolumn{4}{c}{36.92} \\
\hline
\end{tabular}

\section{Results}

3.1. Bending Force of Tubular Grafts. A woven fabric was integrated into the stent to ensure a lightweight but highstrength, flexible, and conformable design [10]. The typical bending process of woven tubular fabric is shown in Figure 4. The bending process of the woven tubular fabric was characterized by the following: (i) radial compression due to the 


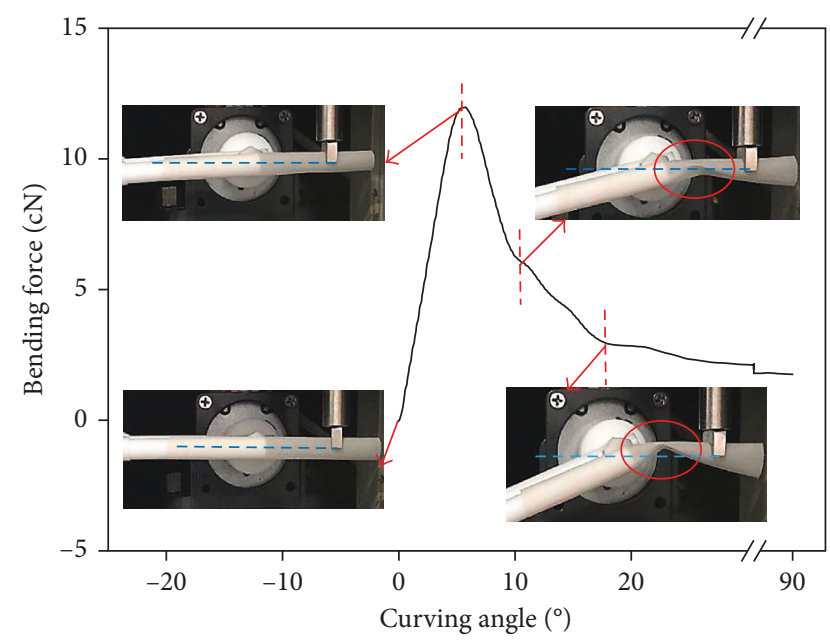

Figure 4: Typical bending curve of tubular fabric (blue dotted line refers to the horizontal position).

semicircular load cell foot that closely held the tubular graft, and no fabric deformation was observed; (ii) fabric started to deform; (iii) onset of fabric collapse and initiation of a kink in the inner curve; and (iv) rotation around the kink point. The maximum bending force was reached at the end of the first stage, which could explain why the maximum curving angle of the three tubular grafts ranged from $4^{\circ}$ to $13^{\circ}$ only (i.e., a relatively small angle). Findings indicate that the kink point was the bending point after deformation, and this kink point was observed in between the designed bending point and testing point. Thus, only the force values of three tubular grafts before the highest bending force were compared.

Figure 5(a) illustrates the bending force of three tubular grafts (G1, G2, and G3) with corresponding stent graft bending arm lengths. Figure 5(a) shows the lower bending force of G1 compared with those of G2 and G3 given the same curving angle. At the curving angle of $5^{\circ}$, the bending force values of G1, G2, and G3 were 5.98, 12.89, and $11.31 \mathrm{cN}$, respectively.

The bending arm lengths of G1, G2, and G3 were 29.42, 36.92 , and $44.42 \mathrm{~mm}$, respectively. When bending force reached the maximum, tubular graft G1 obtained a higher curving angle than G2 and G3 (Figure 5(b)). No statistical difference was observed between G2 and G3.

3.2. Spring-Back Force of Tubular Grafts. Spring-back force was estimated from a bigger curving angle to smaller curving angle. The spring-back force of the tubular grafts at the curving angle of $5^{\circ}$ is shown in Table 4 . The spring-back force of G1 with a bending arm length of $29.42 \mathrm{~mm}$ is lower than that of G2 with a bending arm length of $36.92 \mathrm{~mm}$ and G3 with a bending arm length of $44.42 \mathrm{~mm}$.

3.3. Bending Force of Stent Grafts. The bending forces of seven stent grafts were tested separately. Stent spacing was designated as the variable of Group A. The bending force of stent grafts A11, A22, and A33 given the same curving angle is shown in Figure 6. Stent graft A11 obtained the highest

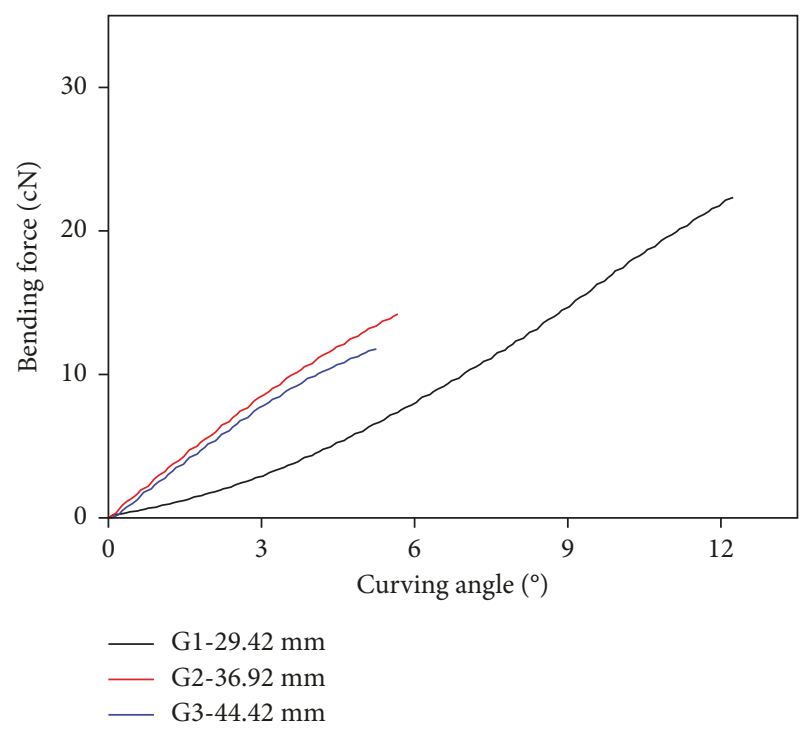

(a)

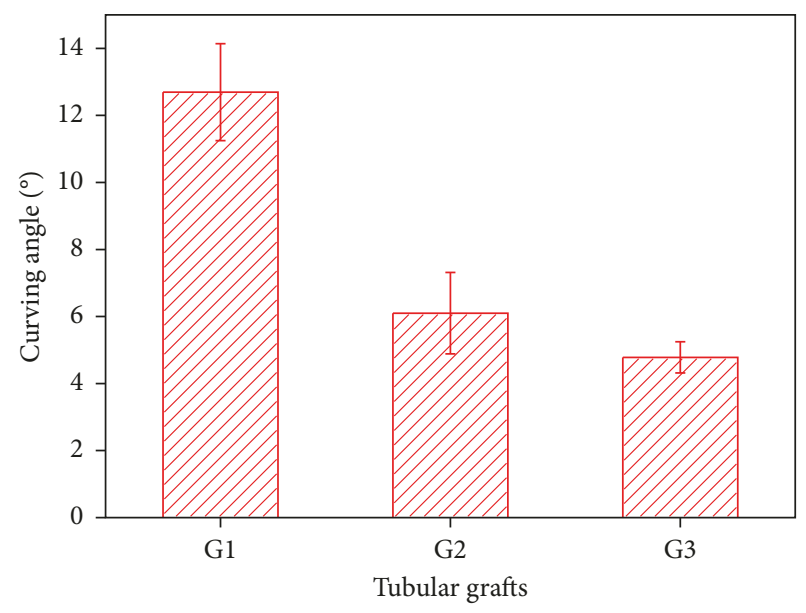

(b)

Figure 5: (a) Bending force curve and (b) curving angle when bending force reached the maximum. Bending arm lengths of tubular grafts and corresponding stent grafts: tubular graft G1 corresponds to A11 (29.42 mm), tubular graft G2 corresponds to A22 $(36.92 \mathrm{~mm})$, and tubular graft G3 corresponds to A33 (44.42 mm).

TABLE 4: Spring-back force of three tubular grafts at the curving angle of $5^{\circ}$ with three bending arm lengths $(\mathrm{cN})$.

\begin{tabular}{lccc}
\hline \multirow{2}{*}{ Tubular graft number } & \multicolumn{3}{c}{ Bending arm length $(\mathrm{mm})$} \\
& 29.42 & 36.92 & 44.42 \\
\hline G1 & $1.09 \pm 0.63$ & - & - \\
G2 & - & $5.67 \pm 0.21$ & - \\
G3 & - & - & $5.53 \pm 0.78$ \\
\hline
\end{tabular}

bending force given the same curving angle. When the stent spacing of A11, A22, and A33 was increased by $5 \mathrm{~mm}$, the corresponding bending forces at $30^{\circ}$ were $57.56,23.22$, and $11.93 \mathrm{cN}$, respectively. Bending force decreased at $30^{\circ}$ by $59.7 \%$ when stent spacing increased from $5 \mathrm{~mm}$ to $10 \mathrm{~mm}$ 

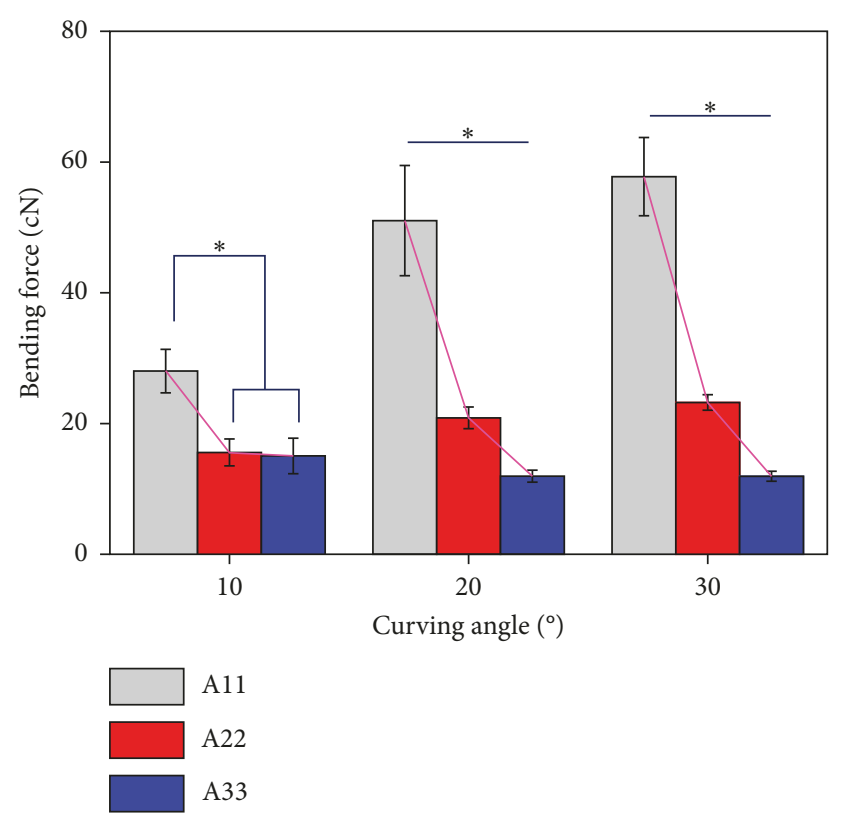

Figure 6: Bending force of stent grafts A11, A22, and A33 given the same curving angle.

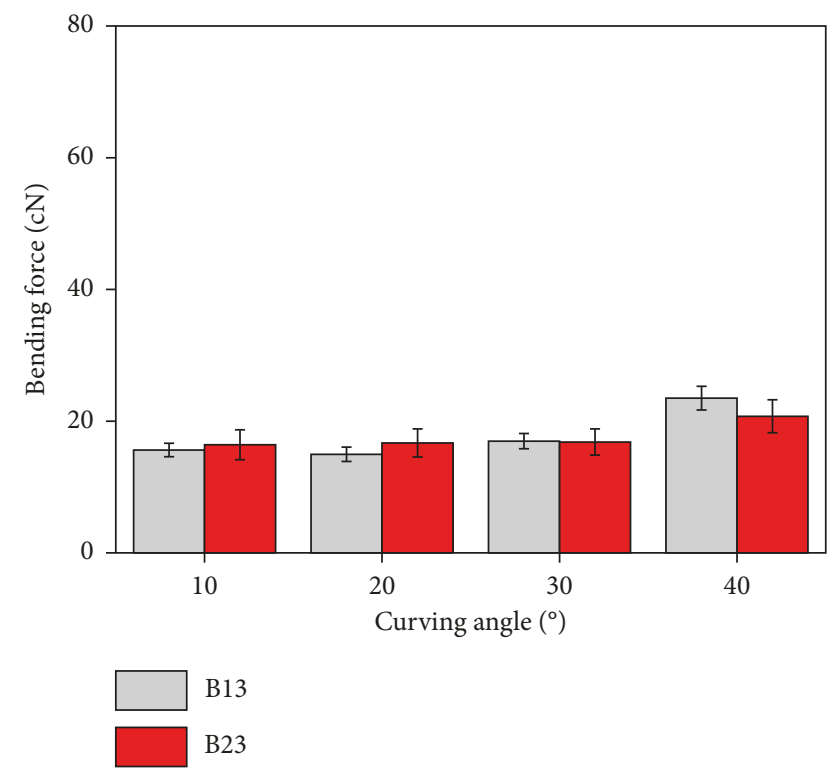

FIGURE 7: Bending force of stent grafts B13 and B23 given the same curving angle.

and decreased by $48.6 \%$ when stent spacing increased from $10 \mathrm{~mm}$ to $15 \mathrm{~mm}$.

No significant difference was found between A22 and A33 at the curving angle of $10^{\circ}$. By contrast, when the curving angle increased to $20^{\circ}$ and $30^{\circ}$, a significant difference was observed between A22 and A33.

Different apex angles were observed in Group B; the apex angles of B13 and $\mathrm{B} 23$ were $30^{\circ}$ and $45^{\circ}$, respectively. The bending force average value of B23 was lower than that of B13 at the curving angle of $40^{\circ}$. However, no significant difference in bending force was observed between B13 and B23 given the same curving angles of $10^{\circ}, 20^{\circ}, 30^{\circ}$, and $40^{\circ}$

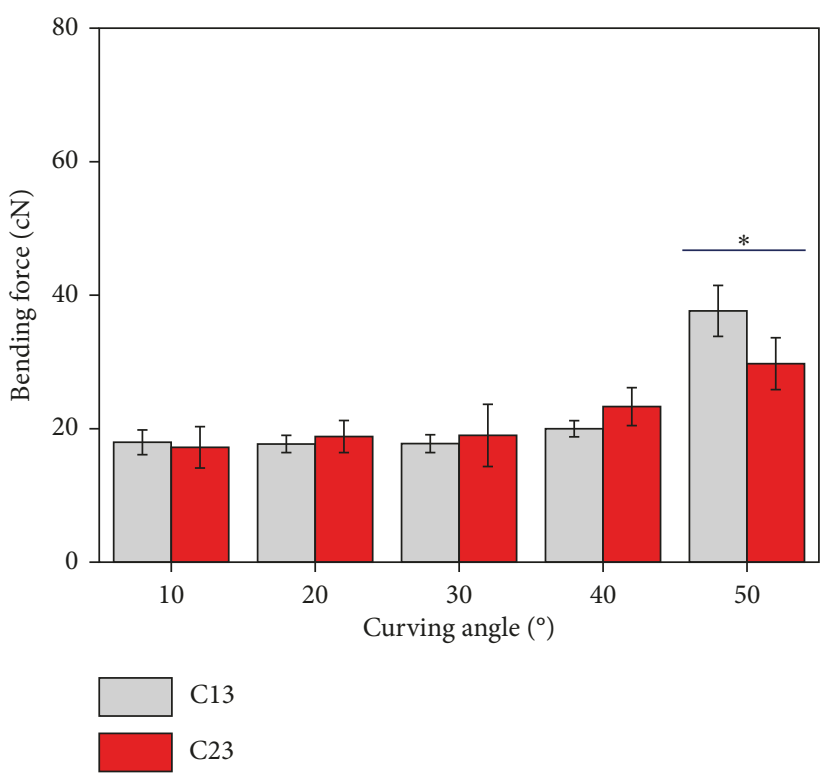

FIGURE 8: Bending force of stent grafts $\mathrm{C} 13$ and $\mathrm{C} 23$ given the same curving angle.

(Figure 7). And the forces did not show statistical difference among different curving angles of $10^{\circ}, 20^{\circ}$, and $30^{\circ}$.

The bending force of stent grafts $\mathrm{C} 13$ and $\mathrm{C} 23$ is shown in Figure 8. No significant difference in bending force was observed between $\mathrm{C} 13$ and $\mathrm{C} 23$ given the same curving angles of $10^{\circ}, 20^{\circ}, 30^{\circ}$, and $40^{\circ}$. However, the bending force of $\mathrm{C} 13$ differs prominently from that of $\mathrm{C} 23$ at the curving angle of $50^{\circ}$.

The number of struts per hoop of $\mathrm{C} 13$ and B23 was 4 . The type of stent of $\mathrm{C} 13$ was M-stented, whereas B23 was Z-stented. Their bending force was compared, and no significant difference existed given the same curving angle.

3.4. Spring-Back Force of Stent Grafts. The spring-back force of the stent grafts of Group A with the same curving angles is shown in Figure 9. The spring-back force of the three samples increased when the curving angle widened from $10^{\circ}$ to $30^{\circ}$. Meanwhile, when the stent spacing of A11, A22, and A33 increased, the spring-back force decreased, especially at the relatively large angles of $20^{\circ}$ and $30^{\circ}$. When the curving angle was $20^{\circ}$, the spring-back forces of A22 and A33 were not significantly different and statistically lower than that of A11. When the curving angle was $30^{\circ}$, the spring-back forces differed. The spring-back force was almost linear with the increase of stent spacing at the higher slope of $30^{\circ}(8.24)$ unlike for those at $20^{\circ}$ (3.87). The gap between A11 and A22 at $30^{\circ}$ was $10.12 \mathrm{cN}$, which was higher than that at $20^{\circ}$ $(4.79 \mathrm{cN})$. The gap between $\mathrm{A} 22$ and $\mathrm{A} 33$ at $30^{\circ}$ was $6.32 \mathrm{cN}$, which was also higher than that at $20^{\circ}(2.95 \mathrm{cN})$.

The spring-back force of Group B increased as the curving angle increased (Figure 10), and this result was consistent with that of Group A. No difference was observed at the relatively low angle of $20^{\circ}$. However, significant differences were observed when the curving 


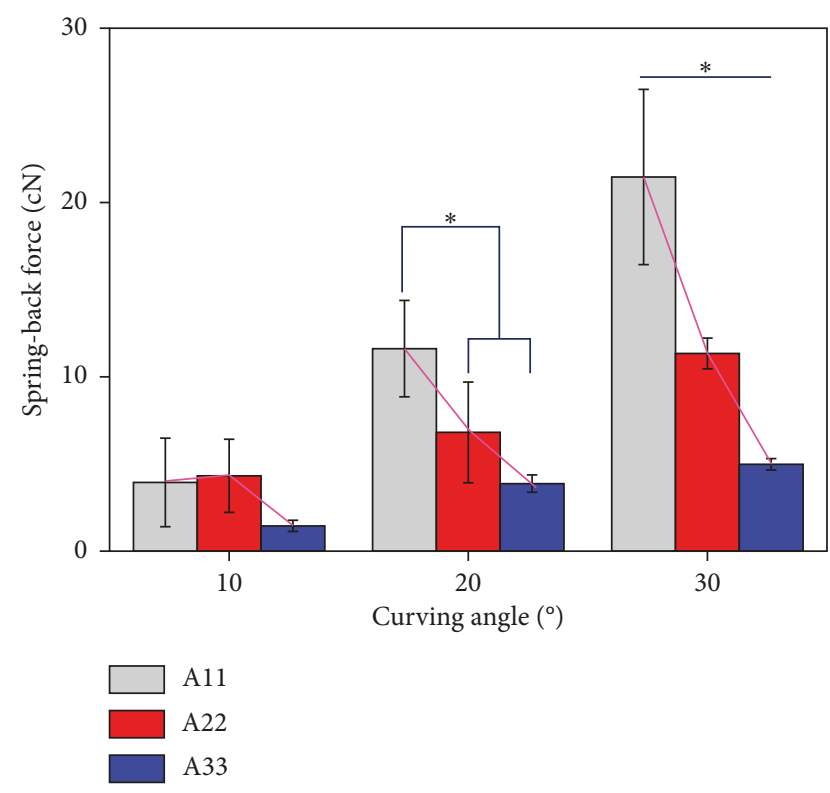

FIGURE 9: Spring-back force of stent grafts A11, A22, and A33 with the same curving angle.

angles increased to the relatively high angles of $30^{\circ}$ and $40^{\circ}$. The spring-back force of B13 was higher than that of $\mathrm{B} 23$ at the curving angles of $30^{\circ}$ and $40^{\circ}$. The ratios of the spring-back forces of B13 and B23 were 1.28 and 1.50, respectively. The ratios increased when curving angles reached $30^{\circ}$ and $40^{\circ}$.

The spring-back force of Group C (Figure 11) increased when the curving angle increased, and this tendency was observed in all of the stent graft samples. No significant difference was observed between $\mathrm{C} 13$ and $\mathrm{C} 23$ in all stent apex angles. The spring-back force of B23 was lower than that of $\mathrm{C} 13$ given the same curving angle.

\section{Discussion}

Spring-back force in proximal SINE can be potentially risky for patients. Spring-back force is exerted by stent grafts that have been passively bent along curved arteries such as the aortic arch. Regardless of stent graft type, flexibility is highly necessary. Stent graft inflexibility has been an issue for many years, and designing stent grafts to achieve optimum flexibility requires further study. Most of the commonly used commercial stent grafts are Z-stented, such as C-TAG and TAG (W. L. Gore \& Associates, Newark, Del.) and Valiant (Medtronic, Minneapolis, Minn.).

This study focused on the structural design of Z-type stent grafts. The bending and spring-back forces of seven stent-graft prototypes were tested with the newly designed device to ensure that the force tested was perpendicular to the stent graft surface. In this scenario, force data could be effectively obtained in various curving conditions.

Bending force and spring-back force are good indicators of stent-graft flexibility. Bending force can be induced on the stent graft from the outside to make it curved, whereas spring-back force is exerted by the stent graft when it is

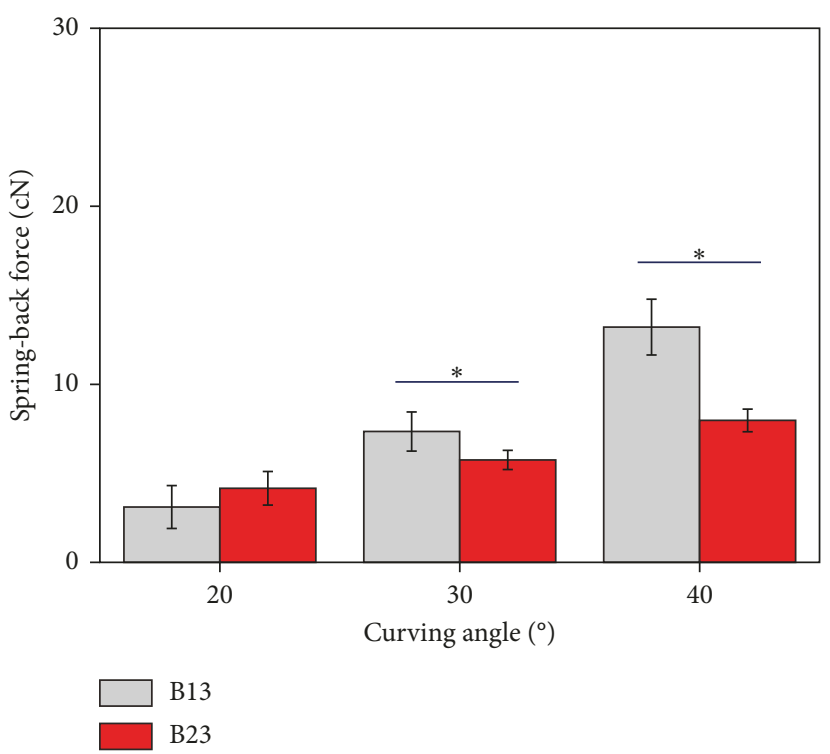

FIGURE 10: Spring-back force of stent grafts B13 and B23 given the same curving angle.

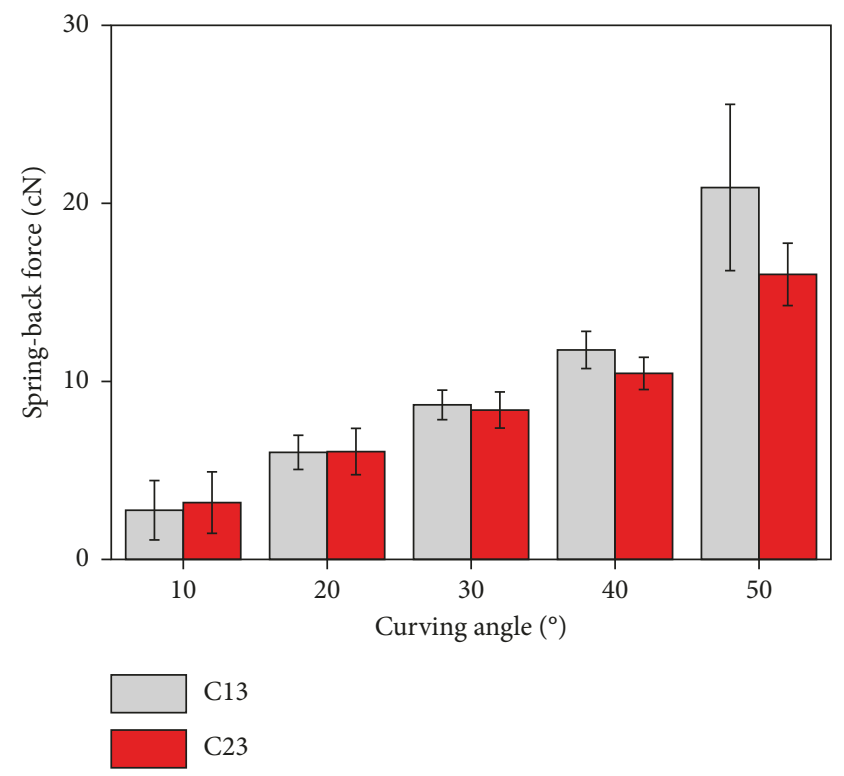

FIgURE 11: Spring-back force of stent grafts C13 and C23 given the same curving angle.

passively curved. These two forces come from opposite directions, and bending force is higher than spring-back force. When a tubular fabric is bent, bending and tensile strain can be observed outside of the bend [30], whereas the inside of the bend is compressed and the fabric buckles [31]. Fiber resistance (i.e., generalized linear viscoelasticity) and interfiber friction are two important factors of woven fabric resistance to bending [32]. Interfiber friction increases bending resistance and impedes recovery from deformation [33] (i.e., spring-back process). Strain energy is stored within an elastic solid if the solid is deformed by applying forces [34]. Thus, the elastic recovery of the fiber determines the 
deformation recovery of the fabric [35]. The interfiber friction and stress-strain behavior of the fiber ultimately result in energy loss. NiTi is a nonlinear material. Strain energy is stored and turned into kinetic energy [36] when the nitinol stent is deformed and recovered. Thus, the deformation process of NiTi stent is accompanied by energy loss $[37,38]$. Subsequently, owing to the energy loss, the spring-back force of stent grafts is lower than its corresponding bending force.

In this study, the forces of tubular graft G1 were the lowest. However, the corresponding stent graft A11 obtained the highest bending and spring-back forces except in the spring-back angle of $10^{\circ}$. This finding indicates that the metal stent in the stent graft influenced the bending or spring-back force level of the stent graft more than tubular fabric graft. The tubular fabric incorporated into the stent was free of kink unlike in the tubular fabric alone during bending. This finding may be attributed to the shape-holding capacity of the metal stent, which helped maintain the circular form of the tubular fabric cross section.

The results of Group A indicate that the longer the stent spacing is, the lower the bending or spring-back forces will be. Long stent spacing suggests less stent portion within the arm length. The ratios between the stent portion length and arm length were $74.5 \%, 59.4 \%$, and $49.3 \%$ for A 11 , A22, and A33, respectively. Thus, force level is dependent on the stent. A longer stent spacing results in a lower force level.

Bending force decreased by $59.7 \%$ when stent spacing increased from $5 \mathrm{~mm}$ to $10 \mathrm{~mm}$ and decreased by $48.6 \%$ when stent spacing increased from $10 \mathrm{~mm}$ to $15 \mathrm{~mm}$. Stent spacing changed the flexibility of stent graft dramatically, as evidenced by their negative correlation. As stent spacing became longer, force decrease percentage decreased. This finding implies that decreasing bending force by simply increasing stent spacing is an ineffective approach.

The bending force of A22 and A33 showed no difference in the curving angle of $10^{\circ}$. However, bending force was statistically different in the curving angles of $20^{\circ}$ and $30^{\circ}$. The difference in the spring-back forces of A11, A22, and A33 increased gradually when the curving angle increased. The result indicated that the effect of stent spacing on flexibility could be amplified by increasing the curving angle. Increasing the curving angle resulted in a higher deformation of the stent graft. The longer stent spacing implies a long fabric section in between stent wires, which is more prone to deformity compared with that of a nitinol stent.

The arm lengths of the three samples were not the same. Engineering mechanics states that the shorter an arm is, the higher the force will be. Therefore, the highest force of stent graft A11 can be attributed to two aspects: short stent spacing and short arm length. Assuming that the arm length of the three samples is the same, a shorter stent spacing (e.g., A11) indicates a more stented section in the freebending or spring-back arm, whereas a longer stent spacing (e.g., A33) shows a less stented section. The metal stent is considered to be the crucial factor increasing the results of bending or spring-back force. Accordingly, the assumed condition is similar to the findings obtained by this study.
The results of Group B indicate that relatively big apex angle can reduce spring-back force. A big apex angle implies more continuous fabric in the stented section. Deformation was observed in the fabric in between stent struts unlike in the continuous fabric in the stented section. As the semicircular force cell foot was used in this study, morphology of the stented section was maintained within the relatively small curving angle. The continuous fabric in the stented section may be deformed by a big curving angle, which in turn may result in the spring-back force difference between $\mathrm{B} 13$ and B23 at the curving angles of $30^{\circ}$ and $40^{\circ}$.

A bigger apex angle implies fewer stent apexes of single stent wires with the same diameter; however, radial strength could decrease. The radial strength of stent grafts provides effective support for blood vessels, maintains sufficient luminal patency, and secures fixation to the artery wall [39]. Therefore, a balance of spring-back force and radial support force is needed when designing a new generation stent graft.

The bending force of $\mathrm{C} 13$ was higher than $\mathrm{C} 23$ in the relatively high angle of $50^{\circ}$. Bending force was related to the apex angle. In Group C, the apex angle of $\mathrm{C} 13$ was smaller than that of C23; this result was consistent with those in Group B. The spring-back force of $\mathrm{B} 23$ was lower than that of $\mathrm{C} 13$ given the same curving angle. Thus, Z-stented grafts could help reduce rigidity unlike $\mathrm{M}$-stented grafts. A possible explanation for these findings is that the number of continuous fabric in Z-stented grafts is higher than that in M-stented grafts when the number of struts per hoop is the same.

The overall relationship between stent graft structures and bending force or spring-back force illustrates the relationship between stent graft structure and its flexibility.

The flexibility of commercial stent grafts used at present was rarely evaluated. Demanget et al. [9] evaluated the flexibility with the luminal reduction rate and approved that the stent design strongly influences flexibility of commercial aortic stent grafts. The luminal reduction rate result of three Z-stented commercial stent grafts Endurant (Medtronic, CA, USA), Zenith Flex, and Zenith LP (Cook, Bjaeverskov, Denmark) is shown in Table 5. However, the structural parameters of those three Z-stented commercial stent grafts were different, it is not reasonable to compare their flexibility directly. So the ratio of stent spacing to stent height was calculated and regarded as relative stent spacing. The luminal reduction rate at $90^{\circ}$ of three stent grafts is all no more than $20 \%$. The numerical relationship of luminal reduction rate level of those three commercial stent grafts is the same with that of the ratio of stent spacing to stent height. This result is consistent with our result that longer stent spacing helps us to enhance flexibility.

Bending and spring-back forces of other two commercially available Z-stented commercial stent grafts, Valiant (Medtronic, CA, USA) and Zenith TX2 2PT (Cook, Bjaeverskov, Denmark), were tested with the same testing method used in this research (Table 6). Bending force was higher than spring-back force for all stent grafts. Zenith TX2 2PT showed lower bending and spring-back forces. The numerical relationship of force per bending arm length at $50^{\circ}$ between Valiant and Zenith TX2 2PT is opposite to that of 
TABLE 5: Luminal reduction rate of commercial stent grafts.

\begin{tabular}{|c|c|c|c|c|c|}
\hline Stent grafts & Length of graft $(\mathrm{mm})$ & Stent spacing $(\mathrm{mm})$ & Stent height $(\mathrm{mm})$ & $\begin{array}{l}\text { Ratio of stent spacing } \\
\text { to stent height }\end{array}$ & $\begin{array}{l}\text { Luminal reduction } \\
\text { rate level at } 90^{\circ}\end{array}$ \\
\hline Endurant & 91.5 & 2.1 & 8.3 & 0.25 & Low \\
\hline Zenith Flex & 99.4 & 5.8 & 11.7 & 0.50 & High \\
\hline Zenith LP & 92.9 & 3.4 & 8.6 & 0.40 & Medium \\
\hline
\end{tabular}

TABLE 6: Bending and spring-back forces of commercial stent grafts.

\begin{tabular}{|c|c|c|c|c|c|c|c|c|c|}
\hline \multirow[t]{2}{*}{$\begin{array}{l}\text { Stent } \\
\text { grafts }\end{array}$} & \multirow[t]{2}{*}{$\begin{array}{l}\text { Diameter } \\
(\mathrm{mm})\end{array}$} & \multirow[t]{2}{*}{$\begin{array}{l}\text { Bending arm } \\
\text { length }(\mathrm{mm})\end{array}$} & \multirow[t]{2}{*}{$\begin{array}{l}\text { Stent spacing } \\
\quad(\mathrm{mm})\end{array}$} & \multirow[t]{2}{*}{$\begin{array}{l}\text { Stent height } \\
(\mathrm{mm})\end{array}$} & \multirow[t]{2}{*}{$\begin{array}{l}\text { Ratio of stent spacing to } \\
\text { stent height }\end{array}$} & \multicolumn{2}{|c|}{ Force at $50^{\circ}(\mathrm{cN})$} & \multicolumn{2}{|c|}{$\begin{array}{l}\text { Force per } \\
\text { bending arm } \\
\text { length at } 50^{\circ} \\
\left(\mathrm{cN} \cdot \mathrm{mm}^{-1}\right)\end{array}$} \\
\hline & & & & & & Bending & $\begin{array}{l}\text { Spring- } \\
\text { back }\end{array}$ & Bending & $\begin{array}{l}\text { Spring- } \\
\text { back }\end{array}$ \\
\hline Valiant & 32 & 34 & 2.5 & 15.5 & 0.16 & 140.04 & 59.98 & 4.12 & 1.76 \\
\hline $\begin{array}{l}\text { Zenith } \\
\text { TX2 2PT }\end{array}$ & 40 & 53 & 11.0 & 16.0 & 0.69 & 59.98 & 10.34 & 1.13 & 0.19 \\
\hline
\end{tabular}

the ratio of stent spacing to stent height. This is also consistent with the result that longer stent spacing contributes to enhancing flexibility. However, due to the differences in structure parameter and size specification between the commercial stent grafts, it is therefore difficult to conclude which one is the most flexible immediately.

This study attempted to enhance the understanding as to how stent graft structure could affect clinical results such as complications of proximal SINE. The spring-back force causing proximal SINE was analyzed. The stent graft with long stent spacing, large apex angle, and Z-type stent strut configuration can help decrease complication rates.

Other properties (i.e., radial force) that could affect clinical results are needed to be studied. Predicting clinical outcomes on the basis of bending and spring-back forces is challenging. Nonetheless, results on the bending and springback forces can help with the design and choice of stent grafts from the perspective of flexibility decreasing the incidence of proximal SINE. A complicated interaction exists between stent graft and host artery, and other factors may be considered in anticipation of clinical results. In vitro animal model research may be conducted to establish the relationship between stent graft design and potential clinical results.

\section{Conclusions}

Proximal SINE as a form of TEVAR complication has attracted wide attention. SINE formation can be attributed to stent graft inflexibility. In this study, bending force and spring-back force were estimated to evaluate the flexibility of endovascular stent grafts. The relationship between structural design factors and flexibility was also determined, the results of which may be used for designing new generation stent grafts. Findings showed that long stent spacing, large apex angle, and Z-stented strut configuration are potential structural designs of stent grafts. Results can help engineers design and improve stent graft structures and guide clinicians on the best types of stent grafts. The best stent grafts are those with excellent comprehensive performance, particularly, high levels of flexibility.

\section{Conflicts of Interest}

The authors declare that there are no conflicts of interest regarding the publication of this paper.

\section{Acknowledgments}

This work was financially supported by the National Natural Science Foundation of China (81371648 and 81770508), the Fundamental Research Funds for the Central Universities (BCZD2016011, 15D110126, 17D110113, and 17D110117), and the 111 Project Biomedical Textile Materials Science and Technology (B07024).

\section{References}

[1] P. Cao, F. Verzini, P. De Rango, G. Maritati, F. De Pasquale, and G. Parlani, "Different types of thoracic endografts," Journal of Cardiovascular Surgery, vol. 50, no. 4, pp. 483-492, 2009.

[2] D. Bockler, J. Brunkwall, P. R. Taylor et al., "Thoracic endovascular aortic repair of aortic arch pathologies with the conformable thoracic aortic graft: early and 2 year results from a European multicentre registry," European Journal of Vascular and Endovascular Surgery, vol. 51, no. 6, pp. 791-800, 2016.

[3] Y. Guan, L. Wang, J. Lin, and M. W. King, "Compliance study of endovascular stent grafts incorporated with polyester and polyurethane graft materials in both stented and unstented zones," Materials, vol. 9, no. 8, p. 658, 2016.

[4] J. Lin, R. Guidoin, J. Du et al., "An in vitro twist fatigue test of fabric stent-grafts supported by Z-stents vs. ringed stents," Materials, vol. 9, no. 2, p. 113, 2016.

[5] M. Malina, J. Brunkwall, K. Ivancev et al., "Late aortic arch perforation by graft-anchoring stent: complication of endovascular thoracic aneurysm exclusion," Journal of Endovascular Surgery, vol. 5, no. 3, pp. 274-277, 1998. 
[6] M. Boufi, C. Guivier-Curien, A. D. Loundou et al., "Morphological analysis of healthy aortic arch," European Journal of Vascular and Endovascular Surgery, vol. 53, no. 5, pp. 663-670, 2017.

[7] T. A. Chuter, "The choice of stent-graft for endovascular repair of abdominal aortic aneurysm," Journal of Cardiovascular Surgery, vol. 44, no. 4, pp. 519-525, 2003.

[8] C. Singh and X. Wang, "A biomechanically optimized knitted stent using a bio-inspired design approach," Textile Research Journal, vol. 86, no. 4, pp. 380-392, 2016.

[9] N. Demanget, A. Duprey, P. Badel et al., "Finite element analysis of the mechanical performances of 8 marketed aortic stent-grafts," Journal of Endovascular Therapy, vol. 20, no. 4, pp. 523-535, 2013.

[10] J. M. Weidman, M. Desai, A. Iftekhar et al., "Engineering goals for future thoracic endografts-how can we make them more effective?," Progress in Cardiovascular Diseases, vol. 56, no. 1, pp. 92-102, 2013.

[11] F. R. Arko, W. A. Lee, B. B. Hill, P. Cipriano, T. J. Fogarty, and C. K. Zarins, "Increased flexibility of AneuRx stent-graft reduces need for secondary intervention following endovascular aneurysm repair," Journal of Endovascular Therapy, vol. 8, no. 6, pp. 583-591, 2001.

[12] K. Lee, E. Leci, T. Forbes, L. Dubois, G. DeRose, and A. Power, "Endograft conformability and aortoiliac tortuosity in endovascular abdominal aortic aneurysm repair," Journal of Endovascular Therapy, vol. 21, no. 5, pp. 728-734, 2014.

[13] C. A. Nienaber, S. Kische, and H. Ince, "Thoracic aortic stentgraft devices: problems, failure modes, and applicability," Seminars in Vascular Surgery, vol. 20, no. 2, pp. 81-89, 2007.

[14] L. Canaud, F. Joyeux, J. P. Berthet, K. Hireche, C. Marty-Ane, and P. Alric, "Impact of stent-graft development on outcome of endovascular repair of acute traumatic transection of the thoracic aorta," Journal of Endovascular Therapy, vol. 18, no. 4, pp. 485-490, 2011.

[15] Z. Dong, W. Fu, Y. Wang et al., "Stent graft-induced new entry after endovascular repair for Stanford type B aortic dissection," Journal of Vascular Surgery, vol. 52, no. 6, pp. 1450-1457, 2010.

[16] Z. H. Dong, W. G. Fu, Y. Q. Wang et al., "Retrograde type A aortic dissection after endovascular stent graft placement for treatment of type B dissection," Circulation, vol. 119, no. 5, pp. 735-741, 2009.

[17] A. H. M. Bashar, T. Kazui, N. Washiyama, H. Terada, K. Yamashita, and M. E. Haque, "Mechanical properties of various Z-stent designs: an endovascular stent-grafting perspective," Artificial Organs, vol. 27, no. 8, pp. 714-721, 2003.

[18] D. B. Kim, H. Choi, S. M. Joo et al., "A comparative reliability and performance study of different stent designs in terms of mechanical properties: foreshortening, recoil, radial force, and flexibility," Artificial Organs, vol. 37, no. 4, pp. 368-379, 2013.

[19] G. P. Kumar, F. Kabinejadian, J. Liu, P. Ho, H. L. Leo, and F. Cui, "Simulated bench testing to evaluate the mechanical performance of new carotid stents," Artificial Organs, vol. 41, no. 3, pp. 267-272, 2017.

[20] N. Demanget, P. Latil, L. Orgeas et al., "Severe bending of two aortic stent-grafts: an experimental and numerical mechanical analysis," Annals of Biomedical Engineering, vol. 40, no. 12, pp. 2674-2686, 2012.

[21] A. F. D. P. Freitas, M. D. de Araujo, W. W. Zu, and R. M. E. Fangueiro, "Development of weft-knitted and braided polypropylene stents for arterial implant," Journal of the Textile Institute, vol. 101, no. 12, pp. 1027-1034, 2010.

[22] M. M. C. Hirdes, F. P. Vleggaar, M. de Beule, and P. D. Siersema, "In vitro evaluation of the radial and axial force of self-expanding esophageal stents," Endoscopy, vol. 45, no. 12 , pp. $997-1005,2013$.

[23] H. Isayama, Y. Nakai, Y. Toyokawa et al., "Measurement of radial and axial forces of biliary self-expandable metallic stents," Gastrointestinal Endoscopy, vol. 70, no. 1, pp. 37-44, 2009.

[24] Q. Zou, W. Xue, J. Lin et al., "Mechanical characteristics of novel polyester/NiTi wires braided composite stent for the medical application," Results in Physics, vol. 6, pp. 440-446, 2016.

[25] N. Demanget, S. Avril, P. Badel et al., "Computational comparison of the bending behavior of aortic stent-grafts," Journal of Mechanical Behavior of Biomedical Materials, vol. 5, no. 1, pp. 272-282, 2012.

[26] R. Chiesa, V. Riambau, G. Coppi et al., "The Bolton Treovance abdominal stent-graft: European clinical trial design," Journal of Cardiovascular Surgery, vol. 53, no. 5, pp. 595-604, 2012.

[27] I. Akin, H. Ince, S. Kische, and C. A. Nienaber, "Implication of thoracic aortic stent-graft conformability on clinical outcomes," Acta Chirurgica Belgica, vol. 109, no. 1, pp. 20-26, 2009.

[28] S. A. Crawford, R. M. Sanford, T. L. Forbes, C. H. Amon, and M. G. Doyle, "Clinical outcomes and material properties of in situ fenestration of endovascular stent grafts," Journal of Vascular Surgery, vol. 64, no. 1, pp. 244-250, 2016.

[29] Y. Guan, L. Wang, J. Lin, F. Zhao, F. J. Wang, and G. P. Guan, "Dynamic testing device and method of bending force and spring-back force of endovascular stent graft," Chinese Invention Patent, 2017.

[30] N. J. Abbott, M. J. Coplan, and M. M. Platt, "102-theoretical considerations of bending and creasing in a fabric," Journal of Textile Institute Transactions, vol. 51, no. 12, pp. T1384-T1397, 1960.

[31] F. J. Shi, J. L. Hu, and T. X. Yu, "Modeling the creasing properties of woven fabrics," Textile Research Journal, vol. 70, no. 3, pp. 247-255, 2000.

[32] S. J. Grey and G. A. V. Leaf, "21-the nature of inter-fibre frictional effects in woven-fabric bending," Journal of the Textile Institute, vol. 76, no. 5, pp. 314-322, 2008.

[33] P. Grosberg and N. M. Swani, "The mechanical properties of woven fabrics: Part IV: the determination of the bending rigidity and frictional restraint in woven fabrics," Textile Research Journal, vol. 36, no. 4, pp. 338-345, 1966.

[34] M. J. Avanaki and A. A. A. Jeddi, "Theoretical analysis of geometrical and mechanical parameters in plain woven structures," Journal of the Textile Institute, vol. 108, no. 3, pp. 418-427, 2017.

[35] S. Omeroglu, E. Karaca, and B. Becerir, "Comparison of bending, drapability and crease recovery behaviors of woven fabrics produced from polyester fibers having different crosssectional shapes," Textile Research Journal, vol. 80, no. 12, pp. 1180-1190, 2010.

[36] M. Azaouzi, N. Lebaal, A. Makradi, and S. Belouettar, "Optimization based simulation of self-expanding nitinol stent," Materials and Design, vol. 50, pp. 917-928, 2013.

[37] F. Ahlhelm, R. Kaufmann, D. Ahlhelm, M. F. Ong, C. Roth, and W. Reith, "Carotid artery stenting using a novel selfexpanding braided nickel-titanium stent: feasibility and safety porcine trial," Cardiovascular and Interventional Radiology, vol. 32, no. 5, pp. 1019-1027, 2009.

[38] J. M. Jani, M. Leary, A. Subic, and M. A. Gibson, "A review of shape memory alloy research, applications and opportunities," Materials and Design, vol. 56, pp. 1078-1113, 2014.

[39] L. Zhang, X. Chen, and M. H. Liu, "Research of customized aortic stent graft manufacture," IOP Conference Series: Materials Science and Engineering, vol. 187, no. 1, p. 012027, 2017. 


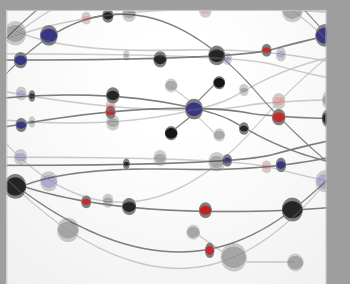

The Scientific World Journal
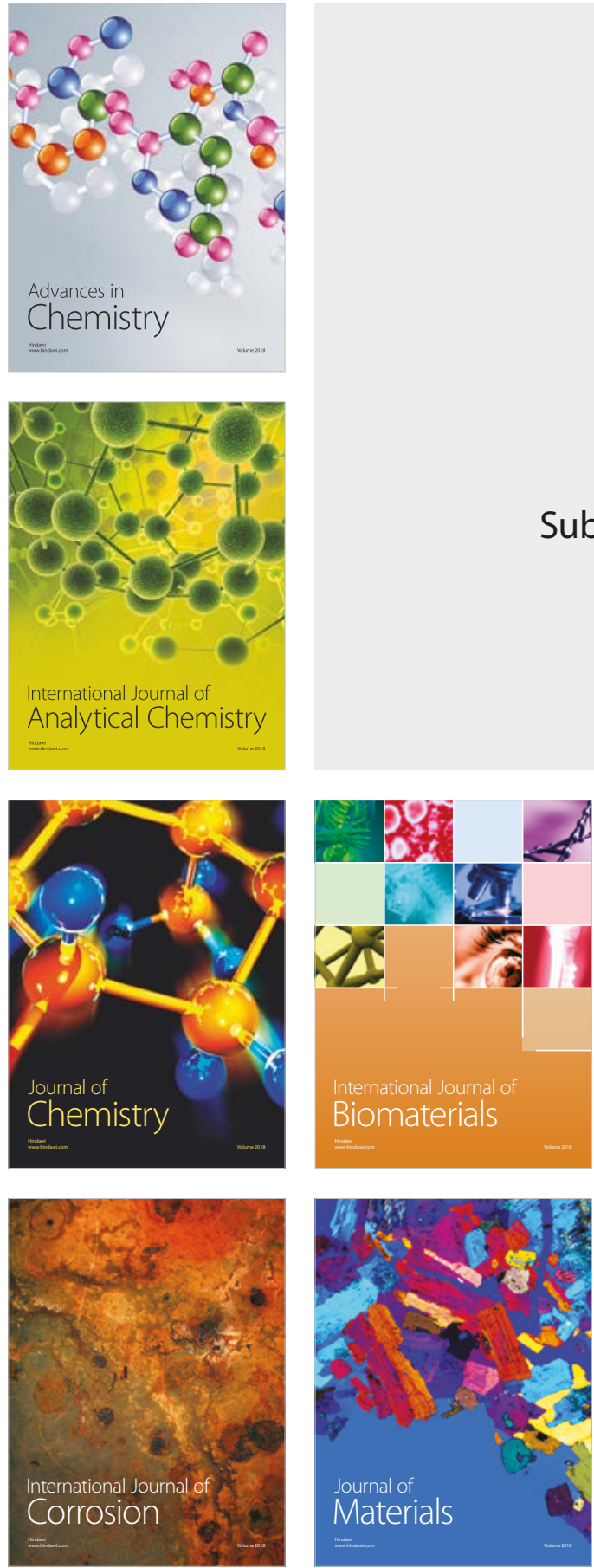

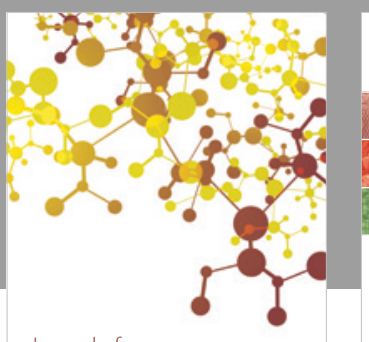

Journal of

Applied Chemistry
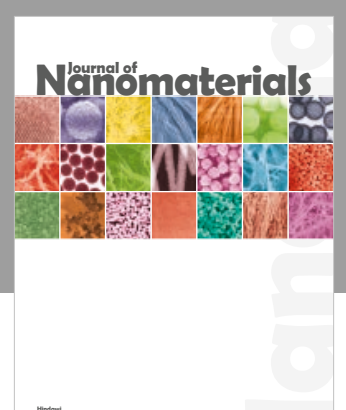

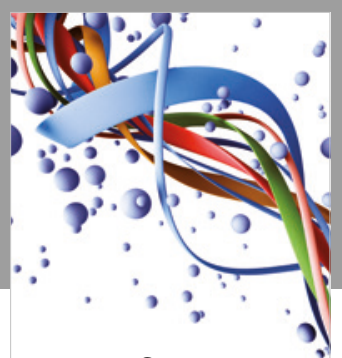

Scientifica

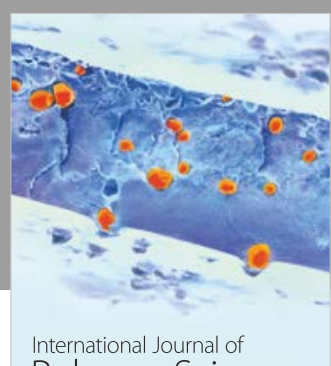

Polymer Science

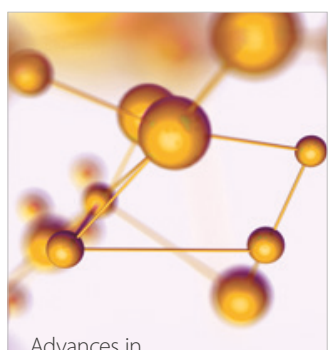

Physical Chemistry
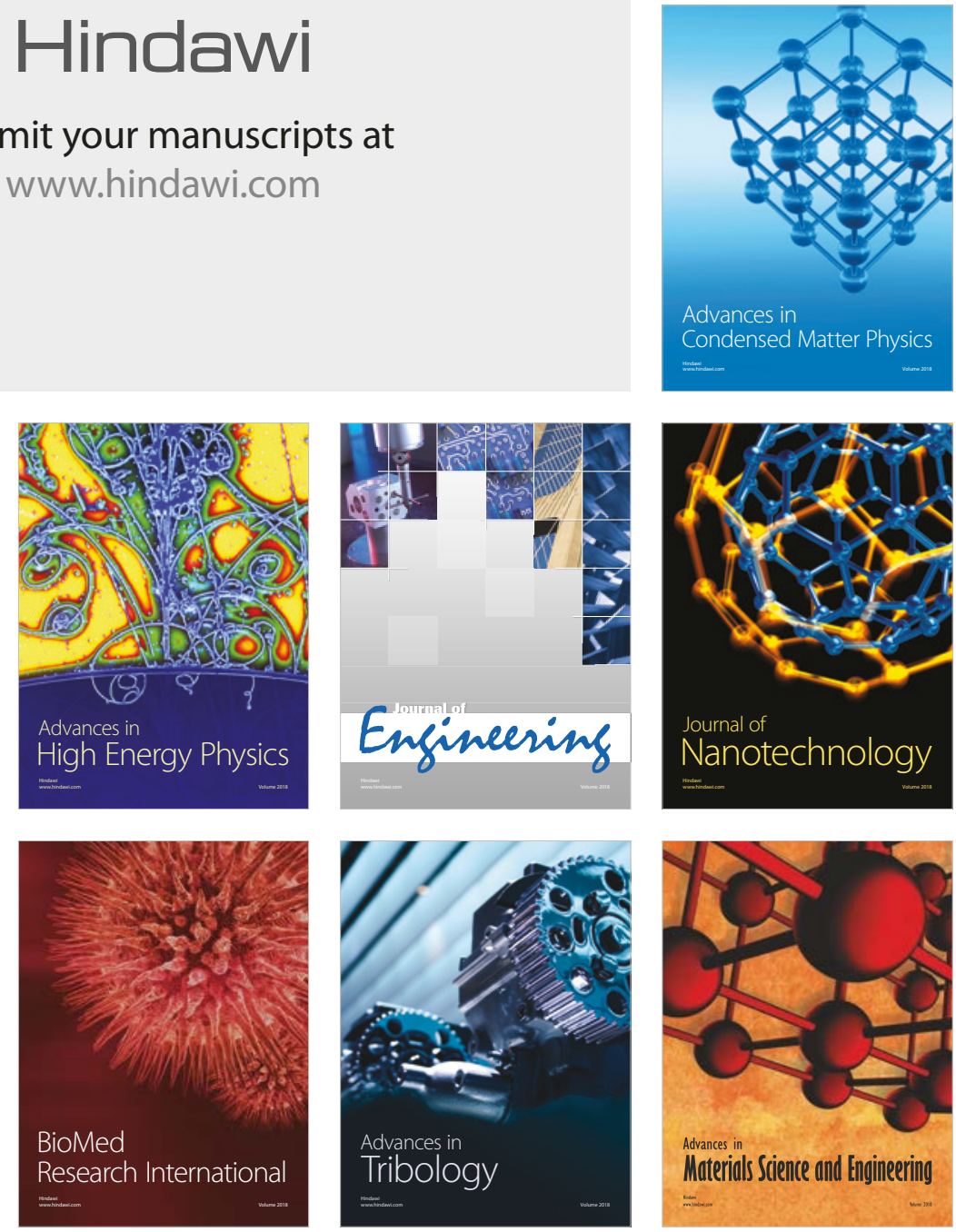